Conclusion This innovative approach to education delivery has embedded the benefits of cross-organisational working and promoted the development of future training sessions such as syringe driver training, verification of expected death training, communication skills training and advance care planning workshops. There is continued momentum for specialist palliative educational input in such care environments, and it is apparent from the evaluation gathered that there is a real desire for this to continue and grow.

\section{P-244 MOVING FORWARD; STRIVING TO IMPROVE UPON ABC END OF LIFE CARE EDUCATION WITHIN CARE HOMES}

Danielle Winch. Garden House Hospice Care, Letchworth, UK

\subsection{6/bmjspcare-2018-hospiceabs.269}

Background The ABC Care Home Education modules are a recognised programme of multi-disciplinary training that has been successfully delivered using a classroom approach. However, the current training does not effectively cover all learning styles, particularly those who are kinaesthetic learners, leaving some attendees struggling to implement learning. Current finance has been established jointly between through the local Clinical Commissioning Group and hospice to continue this work which has provided an opportunity to review and adapt delivery of the programme.

Aims To improve the effectiveness of end of life care education in care homes using clinical interventions including role modelling, ad hoc support and demonstration of practical skills to reinforce learning.

Method Following consultation to establish the ongoing needs of staff a programme of support was offered. This included 'drop in' lunchtime sessions to look at the delivery of practical care, working alongside staff delivering care or supporting with medication and liaising with GPs as appropriate.

Results Although still in its initial stages, the feedback from care home staff and managers has been very positive with staff embracing the opportunity to work alongside an experienced professional. Staff have reported increased confidence leading to improved application of learning, more comprehensive documentation and effective communication. Further work is underway to establish the effect on admissions to hospital within the last year of life and the perceived increase in staff and patient/relative satisfaction.

Conclusion The ABC Education programme has previously established significant strides in improving end of life care within care homes. The review has established that practical input can theoretically improve care further by embracing an increased variety of learning styles and embedding the learning to create established improvements.

\section{P-245 WHAT ITCH DO WE NEED TO SCRATCH? NURSING HOME EDUCATION DELIVERED BY HOSPICES}

Rebecca Harding, Sarah Hill. Severn Hospice, Telford, Shropshire

10.1136/bmjspcare-2018-hospiceabs. 270

Aim End of life care needs to be delivered in a range of care settings with hospice professionals key to promote best practice influencing knowledge, attitudes and behaviours to other healthcare organisations (Hospice UK, 2017). Education and training is key to building these foundations (National Palliative and End of Life Care Partnership, 2015).This study focuses on describing what palliative care education is needed for nurses in nursing homes and does it differ to community nurses' education needs?

Method All nursing homes covered by a Hospice Outreach Nurse Team (HONT) were asked to participate in the study. Questionnaires with a combination of multiple choice questions and free text answers were sent to all nursing homes. Nursing home managers were contacted and permission given before questionnaires sent. The HONT hand-delivered or posted questionnaires with them returned/posted back after six weeks.

Results Questionnaires were sent to 17 Nursing Homes with a return rate of $78 \%$ of the total questionnaires sent. $71 \%$ were registered nurses; only the registered nurse data was collated. Length of time in current post was included with the majority in post for 3 years $+(66 \%)$. Most nurses described themselves as confident and/or competent in palliative care. Respondents replied that core subjects on the current education programme delivered to community nurses by the HONT would improve their care. $65 \%$ of responses stated they had completed palliative care training before with 35\% acknowledging they had had no palliative training of any description. Only $10 \%$ indicated they had completed a university level training in palliative care.

Conclusions and recommendations Nurses in nursing homes want education which deals with broad subjects rather than anything specific. There was a global tone for training rather than specific areas - which suggests that a separate teaching programme is required for nursing home staff.

\section{P-246 WORK EXPERIENCE STUDENTS: EMBRACING CHANGE IN HOSPICE WORKFORCE DEVELOPMENT}

Jenny White. Garden House Hospice Care, Letchworth, UK

10.1136/bmjspcare-2018-hospiceabs.271

Background Traditionally, hospice clinical staff are recruited from acute and community settings. Following a period of significant staff turnover it became apparent that, in keeping with national trends, this pool of experienced staff was diminishing. A decision was made to actively pursue diverse areas of recruitment.

Aims To approach local colleges of further education delivering health care studies at level 2 and 3 and to offer work experience within a hospice setting. It was hoped that this would encourage younger members of staff into hospice services.

Method The local college was approached, and a presentation given to all health care students offering placements in the day services, in-patient and community settings. Eight students requested to undertake their 50 hour placement at the hospice. An Induction Day was delivered including an overview of palliative care, safeguarding and practical care. A pre- and post- questionnaire was given to all students and feedback was sought from the college.

Results With support from tutors, each student was allocated a 'day release.' Only one student was placed in each clinical area at a time and with the high number of students and college holidays, the placements were spread over a five months period. A total of six students completed the placement with 